\title{
CONSIDERAÇÕES SOBRE A EXPERIÊNCIA URBANA DOS LOTEAMENTOS RESIDENCIAIS MURADOS
}

\author{
CONSIDERACIONES SOBRE LA EXPERIENCIA URBANA DE CONJUNTOS \\ RESIDENCIALES CON MUROS
}

\section{CONSIDERATIONS ON THE URBAN EXPERIENCE OF WALL RESIDENTIAL SUBDIVISIONS}

\author{
Murilo Petito CAVALCANTI ${ }^{1}$
}

RESUMO: Condomínios fechados e demais loteamentos residenciais murados têm se destacado nas últimas décadas como produto rentável para o setor imobiliário, sobretudo quando direcionados as camadas mais abastadas da sociedade. O presente trabalho tem por objetivo abordar esses empreendimentos do ponto de vista de seu impacto sobre a morfologia urbana das cidades e das formas de uso e apropriação dos espaços que se originam a partir da imposição da barreira física dos muros.

PALAVRAS-CHAVE: Loteamentos residenciais murados. Condomínios fechados. Morfologia urbana. Espaço público.

RESUMEN: Conjuntos residenciales cerrados y demás lotes residenciales con muros se han destacado en las últimas décadas como un producto rentable para el sector inmobiliario, sobretodo cuando estos son direccionados a las clases sociales más ricas de la sociedad. El trabajo a seguir tiene por objetivo abordar estos emprendimientos del punto de vista de su impacto sobre la morfología urbana de las ciudades y de las formas de uso y apropiación de los espacios que se originan a partir de la imposición de la barrera física de los muros.

PALABRAS CLAVE: Lotes residenciales com muros. Conjuntos residenciales cerrados. Morfología urbana. Espacio publico.

ABSTRACT: Private condominiums and other walled residential subdivisions have been highlighted in recent decades as a rewarding product for the real estate sector, especially when directed to the richer social groups. This paper aims to approach these enterprises from the point of view of their impact on the urban morphology of cities and the forms of use and appropriation of spaces that originate from the imposition of the physical barrier of the walls.

KEYWORDS: Walled residential subdivisions. Private condominiums. Urban morphology. Public space.

${ }^{1}$ Universidade Estadual Paulista (UNESP), Araraquara - SP - Brasil. Mestrando em Ciências Sociais. ORCID: https://orcid.org/0000-0002-4326-5872. E-mail: murilocavalcanti10@gmail.com 


\section{Introdução}

A experiência moderna das cidades, que incluiu os princípios da interação social e da comunicação, transformou-se também num depositário concentrado das inseguranças e dos medos da vida nas cidades. A urbanização capitalista, nesses termos, originou a produção de um novo espaço público, bem como de espaços privados de socialização, na mesma medida em que instituiu novos perigos para as formas de habitar este espaço.

O estabelecimento de uma contradição que podemos definir entre o "viver na cidade" e a "temer a cidade" apontam para o surgimento de mecanismos de segregação e isolamento, já possíveis de serem observados no curso da modernização burguesa do século XIX, como demonstra-se a seguir. As desigualdades presentes nas diferenças de posição no processo produtivo traduziam-se em desigualdades na ocupação do espaço. Estabelecem-se, portanto, tensões relativas à condição de habitar no espaço e suas decorrentes (im)possibilidades de apropriação.

Atualmente, vemos emergir novas estruturas de segregação e isolamento socioespacial. Acompanhadas as inovações dos métodos de acumulação capitalista e o aparecimento de novos mercados, um novo tipo de empreendimento urbano residencial destaca-se como produto imobiliário. Explorar-se-á esse tipo de empreendimento, a que se refere aqui como loteamentos residenciais murados, no transcurso deste trabalho.

Nas últimas décadas do século XX se diversifica e se globaliza um modelo de habitat a que se convencionou denominar condomínios fechados (CFs), ou o que nomeio neste trabalho de loteamentos residenciais murados. Chamo loteamentos residenciais murados procurando evitar incoerências relativas à forma condominial, que aos moldes da $\operatorname{Lei}^{2}$, não se estende a totalidade dos empreendimentos urbanos adaptados a estrutura de moradias enclausuradas que irei abordar. Essa expressão visa abranger exclusivamente a forma horizontal desse tipo de empreendimento urbano, em razão do interesse particular na forma como esses espaços promovem a fragmentação socioespacial.

Entende-se loteamentos residenciais murados como uma formação socioespacial que se baseia: 1) na privatização da segurança; 2) na acessibilidade controlada, vigiada e restrita; 3) num perímetro cercado por muros e câmeras de segurança; 4) em equipamentos internos

${ }^{2}$ Existem duas leis no Brasil que visam estabelecer os parâmetros do parcelamento de novas glebas terras no espaço urbano, a saber: a Lei 4.591, promulgada em 1964, e a Lei 6.766, de 1979 . O regime jurídico condominial está restrito a Lei 4.591. Já a Lei de 1979 estabelece outras diretrizes para o parcelamento urbano. A Lei Federal 13.465/17 acrescenta ao Art. 2 da Lei 6766/79 que se define loteamento de acesso controlado a modalidade de loteamento, cujo controle de acesso será regulamentado pelo Poder Público Municipal, sendo vedado o impedimento de acesso a pedestres ou a condutores de veículos não residentes, devidamente registrados ou cadastrados. 
privatizados de uso coletivo dos residentes. Desse modo, os loteamentos residenciais murados são o que Sposito e Góes (2013) procuraram definir por novos habitats urbanos ${ }^{3}$ e fazem parte do que Caldeira (2011) tomou como enclaves fortificados ${ }^{4}$.

O presente trabalho considera a origem dos atuais loteamentos residenciais murados e as alterações no sentido do espaço público moderno para a compreensão dos dilemas urbanos colocados a partir desses empreendimentos. A hipótese apresentada é a de que os loteamentos residenciais murados são uma alteração substantiva no sentido da modificação da morfologia das cidades e da (re)produção das desigualdades socioespaciais.

\section{A cidade moderna e o novo espaço público:}

Em A situação da classe trabalhadora na Inglaterra, de 1845, Engels narra a edificação da cidade industrial descrevendo a degradação dos bairros operários em contraposição aos espaços de ruas alargadas e de belas fachadas habitados pela burguesia. Enquanto a classe trabalhadora dispunha de ambientes escuros, fétidos, nos quais se proliferava e circulavam todo o tipo de enfermidades, a burguesia dispunha de comodidades de todos os tipos, além de estar distante de toda a degradação que enfrentavam cotidianamente os trabalhadores industriais.

O texto elucida a forma como a desigualdade das condições de morar/habitar esteve presente em larga medida na construção socioespacial da cidade industrial, no curso da modernização burguesa. Verificamos a partir das descrições de Engels como a segregação socioespacial configurou-se como uma marca das cidades erigidas pelo modo de produção burguês. Sobre Manchester, Engels escreve:

A alta burguesia habita vivendas de luxo, ajardinadas, mais longe, em Chorlton e Ardwick ou então nas colinas de Cheetham Hill, Broughton e Pendleton, por onde corre o sadio ar do campo, em grandes e confortáveis casas, servidas, a cada quinze ou trinta minutos, por ônibus que se dirigem ao centro da cidade. A média burguesia vive em ruas boas, mais próximas dos bairros operários, sobretudo em Chorlton e nas áreas mais baixas de Cheetham Hill (ENGELS, 2008, p. 89).

$\mathrm{O}$ paradoxo da cidade moderna exposto por Engels relaciona-se à forma como o progresso material capitalista demonstrou-se incapaz de se traduzir em melhorias para as

${ }^{3}$ São novos habitats urbanos uma vez que "não representam apenas um novo modo de morar, mas sim novas formas de viver e apreender a cidade e o urbano" (SPOSITO; GÓES, 2013, p. 42).

4 "Espaços privatizados, fechados e monitorados para a residência, consumo, lazer ou trabalho" (CALDEIRA, 2011, p. 13). 
condições de habitação das camadas despossuídas. Ao contrário, o que se averiguou foi uma enorme expansão dos espaços de miséria presentes por toda a Inglaterra, onde eram evidentes os contrates entre uma "cidade" de baixa densidade populacional, que dispunha de condições dignas de existência a partir de suas estruturas urbanas, e de uma "cidade" em que os trabalhadores se encontravam amontoados e conviviam com a homogeneidade, a insalubridade, com espaços de pouca ventilação e ruas inóspitas.

O retorno ao ensaio de Engels é uma maneira de observar como o processo de construção de moradias e a própria urbanização foram conduzidos pela atividade burguesa desde os primórdios da cidade industrial. A partir dessa leitura, pode-se afirmar que a segregação socioespacial sempre foi uma característica da cidade capitalista. O distanciamento entre os bairros burgueses e os bairros operários era notório já nos tempos de Engels. Tomando o caso de Manchester como exemplo, observa-se uma gradação entre as classes traduzida de maneira clara no espaço urbano: dos degradantes bairros operários, aos pouco mais próximos bairros da média burguesia e aos bem mais distantes espaços suntuosos da alta burguesia.

O tema da segurança, a busca por proteção e distinção no espaço das cidades, logo, recebera atenção desde a construção da cidade moderna. $\mathrm{O}$ mundo moderno, se por um lado era símbolo de um progresso avassalador que galgou a produção de mercadorias para patamares nunca imaginados, por outro, foi produtor de agudas desigualdades sociais e um aumento exponencial da criminalidade e das inseguranças da vida urbana. Contudo, a despeito da produção de dilemas urbanos relacionados a violência e as inseguranças, a cidade moderna propiciou a construção de um novo espaço público onde eram possíveis as trocas e o contato entre grupos sociais distintos, imersos em grandes aglomerados urbanos, no qual os indivíduos estavam diante de novas condições de afetar-se através das inéditas possibilidades de vida do urbano.

Como observou Jacobs (2000) a cidade moderna remodelou nossas noções de espaço público, trazendo para a vida humana uma dimensão de amplitude com relação às trocas e ao contato com grupos sociais distintos. Esse processo é resultante de uma passagem da vida de comunidade para o urbano, em que as antigas características que compunham a vida comunal já haviam se desintegrado com a experiência moderna das cidades, que se constituíam cada vez mais como espaços de estranhamentos e de contato entre os diversos grupos sociais.

A poesia de Baudelaire é também uma fonte rica para o entendimento das sensações despertadas pela cidade moderna. $\mathrm{O}$ desencantamento com as contradições do desenvolvimento tecnológico habitava o poeta, que buscou através do "flâneur" captar as 
transformações de seu tempo histórico pelos espaços da cidade. Benjamin (2015), inspirado por esta figura heroica da modernidade imortalizada por Baudelaire que é o "flanêur", descreve a Paris oitocentista enquanto ambiente vibrante, território a fervilhar em meio ao nascimento de um conceito de modernidade urbana. $\mathrm{O}$ "flanêur" reaviva no imaginário a ideia de um cidadão transeunte, que consegue tomar a cidade artisticamente numa espécie de distanciamento do caos e da insegurança das cidades modernas, mesmo sem deslocar-se completamente do espaço no qual está inserido. A ideia desse ser que vagueia pela cidade nos remonta aos valores calcados pela experiência da cidade moderna de acessibilidade, livre circulação e mobilidade.

Em Benjamin, o "flâneur" representa justamente o espírito de mobilidade presente na modernidade. Ao percorrer os "boulevares", as ruas e os bares numa espécie de ócio permanente, revela-se um sentimento de curiosidade despertado pela experiência moderna das cidades, num anseio por perceber o que seus novos espaços poderiam significar para a vida humana, além da desigualdade latente e dos aborrecimentos advindos da metropolização.

Já no século XIX, portanto, era possível observar a existência de um ambiente urbano que produzia em escala ampliada as desigualdades socioespaciais em concomitância com a extensão das relações sociais de produção capitalistas, bem como também, ao produzir o espaço, criava condições de apropriação dele. Apropriar-se do espaço, nesse contexto, era estar em relação com um novo espaço público e com as possibilidades de vida urbana que emergiam. A boêmia, o ócio destituído do caráter bucólico, as novas formas de socialização produzidas por espaços de lazer e aglomeração são todas partes integrantes da vida que animava esse nascente cenário urbano.

\section{O século XX e as novas cisões da modernidade: a remodelação das geografias urbanas}

O século XX será palco de mudanças profundas no papel histórico das cidades e em suas formas de apropriação pela vida humana. Como procuro demonstrar a seguir, os traumas da guerra e da destruição das "certezas" da modernidade sólida ${ }^{5}$, nos termos de Bauman (2001), significaram também um rompimento com os valores da experiência moderna das cidades, que passarão a se estruturar com base nos afetos constitutivos da modernidade

\footnotetext{
${ }^{5}$ Bauman define a modernidade sólida como um tempo de elevado equilíbrio entre as estruturas sociais, onde as pessoas viviam segundo uma série de normas, tradições e instituições estáveis. Nesse contexto, a maioria dos membros da classe trabalhadora dispunha de relativa segurança no emprego, o que contribuía para um sentimento de direcionamento e progressividade da vida. Em resumo, a modernidade sólida pode ser caracterizada como um cenário autogarantido, racional, burocraticamente organizado, relativamente previsível e estável.
} 
líquida ${ }^{6}$, sobretudo em relação ao medo, o que balizará o ressurgimento de mecanismos de confinamento e isolamento socioespacial.

A expansão da indústria moderna e a consequente escassez de matérias-primas decorrentes da desenfreada exploração do ambiente natural pela indústria europeia fez com que as burguesias das nações industriais se lançassem a procura de novas fontes de recursos para a continuidade de sua produção, o que envolveu as nações desenvolvidas em duas grandes guerras mundiais no século XX e subjugou a porção subdesenvolvida do globo a exploração desmedida, ao genocídio populacional e ao extermínio da cultura e das tradições desses povos.

Depois da II Guerra Mundial, no contexto da Guerra Fria, um novo modelo estatal emergiu como resposta ao descrédito nos padrões de vida ocidentais. O chamado Estado Social forneceu as bases para uma vida que procuraria se estruturar em torno de um Estado de cunho assistencialista, que desempenharia um papel na provisão de emprego, saúde e bemestar. Ainda que não fosse imune de contradições, o Estado Social, enquanto agente histórico determinante em tempos de modernidade sólida, propiciou níveis de relativa segurança e bem-estar a vida europeia e dos EUA, locais onde se pode dizer que, de fato, o Estado Social existiu por um período.

As contradições entre capital e trabalho já nos anos 1970 e as novas exigências de acúmulo e reprodução do capital, contudo, fariam com que o Estado Social não tivesse vida longínqua. As pressões pelo arrocho salarial, pela desregulamentação e pela liberalização das economias ao redor do globo provocariam uma alteração radical nos papéis do Estado, que se destituiria de suas obrigações em relação a provisão da dignidade da vida de seus cidadãos. Essa passagem, que marca a ascensão do Estado neoliberal, foi acompanhada de uma ideologia do self-made man, aquele indivíduo trabalhador que não depende de assistência externa para ter sucesso profissional e garantias de uma vida confortável e em segurança.

A hipermobilidade dos movimentos do capital (relacionada a desindustrialização e a financeirização), a desregulamentação, o enfraquecimento do poder de barganha do trabalho frente ao capital, decorrente também de um esgarçamento dos sindicatos, as novas formas de contratação na ampliação do trabalho terceirizado, a retirada do Estado da provisão de assistência social na forma de empregos, serviços básicos de saúde e bem-estar e um novo

${ }^{6}$ O termo "líquido" é utilizado por Bauman como uma metáfora para a vida humana caracteriza por ser móvel, amorfa, difícil de conter e predizer. A modernidade líquida é um tempo em que as certezas individuais em relação ao emprego, saúde e bem-estar não mais existem. A noção de "emprego para a vida toda" já não é uma realidade. Os fatores estruturantes da modernidade sólida que calcavam também as identidades dos indivíduos se dissipam, fazendo com que os membros da sociedade se encontrem em estado de permanente indeterminação e de identidades fluídas. 
pacote ideológico de ataque aos movimentos coletivos e incentivo ao esforço individual compõe, sumariamente, as características fundantes desse novo modelo de acúmulo capitalista a que se convencionou chamar de neoliberalismo.

De acordo com Harvey (2011), o capital foi reempoderado em relação ao trabalho pela produção de desemprego e desindustrialização, imigração, deslocalização e toda sorte de mudanças tecnológicas e organizacionais tais como a subcontratação. A partir dos anos 1970, o mundo foi reorganizado segundo os novos princípios neoliberais:

As concepções mentais do mundo foram reformuladas, na medida do possível, com o recurso aos princípios neoliberais da liberdade individual, necessariamente incorporados no livre-mercado e no livre-comércio. Isso exigiu a regressão do Estado de bem-estar social e o sucateamento progressivo do quadro regulatório que tinha sido construído no início dos anos 1970 (como a proteção ambiental). Novas formas de nicho de consumo e estilos de vida individualizados também apareceram de repente, construídos em torno de um estilo pós-moderno de urbanização (a Disneyficação dos centros das cidades e a gentrificação), além do surgimento de movimentos sociais em torno de uma mistura de individualismo egocêntrico, política de identidade, multiculturalismo e preferência sexual (HARVEY, 2011, p. 110).

Esses fatores agrupados fazem parte do que esse e outros autores ${ }^{7}$ leram como uma remodelação das geografias urbanas. Num âmbito global, o capital guarda cada vez menos vínculos com o local. No local, ressurgem mecanismos de confinamento e isolamento socioespacial como resposta a uma nova ordem que tem se revelado caótica, violenta e conturbada. Surgem enclaves de todos os tipos, que contribuem para uma privatização em massa do espaço urbano. Os valores estruturantes da experiência moderna das cidades relacionados a livre-circulação, acessibilidade e mobilidade são pulverizados num ambiente de espaços restritos, controlados e vigiados, com a presença de seguranças particulares e câmeras espalhadas por todos os cantos.

Como acréscimo a segregação, o urbano agora presencia uma fragmentação de larga escala, o que faz com que, nos ambientes onde esse fenômeno é radicalizado, algumas cidades se assemelhem a verdadeiros mosaicos. Como procurou-se demonstrar no início desse trabalho, a segregação socioespacial é um fenômeno anterior a fragmentação, algo também ressaltado por Sposito e Góes (2013). No curso da modernização burguesa, já era possível observar a dissonância entre os bairros operários de péssimas condições de existência e dos suntuosos bairros burgueses. Nos países de modernização tardia também se observava a segregação que acompanhou os processos incipientes da urbanização. No caso brasileiro a

${ }^{7}$ Ver também Davis (2006); Sassen (2016). 
ascensão de moradias irregulares na forma dos cortiços e das favelas era o refúgio dos trabalhadores libertos e de imigrantes que não dispunham de quaisquer condições de abrigarem-se no seio da urbanidade emergente.

Com o avanço do neoliberalismo e as decorrentes alterações nos padrões de vida humana, novos afetos passam a orientar as ações dos indivíduos. O indivíduo "empreendedor de si mesmo", como descreveu Ehrenberg (2010), encontra-se profundamente desprotegido das estruturas sociais que poderiam fornecer um sentimento de segurança para a existência. Nesse contexto, o medo torna-se o afeto primordial da modernidade líquida (BAUMAN, 2001).

As novas relações desse mundo globalizado e fragmentado e as oportunidades de acúmulo de capital para um mercado altamente especulativo como o imobiliário são o ensejo para que se proliferem fortalezas muradas onde seria possível resgatar um estilo de vida seguro e confortável que já não era presente no espaço das cidades.

\section{A origem dos atuais loteamentos residenciais murados}

Em relação a origem dos loteamentos residenciais murados, destacam-se duas teses apresentadas a seguir. A primeira é acerca da inspiração possibilitada pelo modelo de Cidade $\operatorname{Jardim}^{8}$ de Ebenezer Howard (1850 - 1928), como uma espécie de origem ideológica dessa formação socioespacial contemporânea. A segunda liga-se a uma abordagem por uma perspectiva histórica, que aponta que as cidades fortificadas europeias pré-modernas são embrionárias dos atuais loteamentos residenciais murados.

Tomando o modelo de Howard é possível averiguar a existência de mais incompatibilidades do que semelhanças para com a forma atual dos loteamentos residenciais murados. A obra de Howard foi inspirada por uma tentativa de responder aos efeitos urbanos colaterais da industrialização, tais como o aumento da densidade populacional, o do êxodo rural e as precárias condições sanitárias e de moradia nos bairros de trabalhadores assalariados. O ideário howardiano era o de redistribuir a população preservando os valores de comunidade numa nova organização social caracterizada por um centro ocupado por edifícios públicos e um jardim, cruzado por "boulevares" de casas adequadas a preferência e ao gosto de cada morador. $\mathrm{O}$ entorno seria composto por indústrias e comércios.

A despeito das associações possíveis observam-se dois fatores que descreditam a Cidade Jardim como origem ideológica dos loteamentos residenciais murados de hoje. $\mathrm{O}$

\footnotetext{
${ }^{8}$ Tomorrow a Peaceful Path to Real Reform (1898); editado como Garden Cities of Tomorrow (1902).
} 
primeiro diz respeito à propriedade do solo, que se relaciona ao insucesso do modelo de Howard nos EUA. ${ }^{9}$ Howard colocava que o solo da Cidade Jardim deveria ser privado, mas que essa privatização permanecesse coletiva, impossibilitando que os residentes fossem particularmente donos de lotes e unidades de habitação. Os moradores se conformariam a condição de arrendatários. Sobretudo do ponto de vista dos investidores, esse modelo seria de difícil aplicação em terras norte-americanas.

O segundo fator liga-se ao contexto no qual a obra de Howard foi concebida, norteada pela crença no progresso e na razão iluminista como forma de dar fim aos conflitos da sociedade. Raposo (2012) coloca que o pensamento de Howard continha o essencial do ideário iluminista, assim como valores de outras correntes ideológicas como o industrialismo, o apelo romântico à natureza e o universalismo. Esses propósitos contrastam com a forma conservadora dos loteamentos residenciais murados, que não possuem o intento de solucionar as mazelas da cidade, mas configuram-se como locais de refúgio e distinção para as camadas mais abastadas.

A outra tese em questão coloca as cidades fortificadas europeias pré-modernas como o primeiro exemplo histórico do que atualmente se molda na forma dos loteamentos residenciais murados. A menção as muralhas e portões que protegiam as cidades tradicionais das ameaças estrangeiras não parece suficiente para assinalá-las como embriões dos loteamentos residenciais murados fundamentalmente porque essa atual formação socioespacial destaca-se como um dos desdobramentos da segregação socioespacial das cidades burguesas. A cidade moderna guarda poucas relações com sua formação tradicional sobretudo em razão da nova correlação de forças e formas de embate entre as classes sociais em questão. A sociedade moderna inaugura uma era em que os estranhamentos e o contato entre grupos sociais distintos é exacerbado e tensionado em razão da nova divisão social do trabalho, o que inspira medos e receios outrora inexistentes.

Raposo (2012) destaca que a ordem social tradicional não precisava da distância física para garantir suas enormes distâncias sociais. De fato, a modernidade, com o advento da industrialização e da urbanização, traz seu bojo os pressupostos da segregação socioespacial. Os paralelos entre o novo mundo burguês e o acirramento das tensões sociais, que reflete na busca pelo distanciamento socioespacial entre as classes sociais, tem claro exemplo histórico

\footnotetext{
${ }^{9}$ Mckenzie (apud RAPOSO, 2012) destaca o fracasso da experiência norte-americana de Radburn, que abrigou aproximadamente 500 famílias. A promotora City Housing Corporation faliu em 1934. A forma física de Radburn acabou por significar mais uma divisão de subúrbio não condizente com a efetiva redistribuição populacional almejada por Howard.
} 
na operação de Haussmann, em Paris, que visou uma abertura higienista no centro da cidade, local reservado as elites, empurrando as classes subalternas para a periferia da cidade.

Nesse sentido, nos parece verdadeira a afirmativa de Raposo (2012) para quem não se é possível anteceder a meados do século XVIII em relação a existência dos condomínios fechados. Nesse período, ocorreu, em Londres, a privatização de uma praça residencial por um coletivo de residentes. Esse fenômeno foi visto como uma "representação de uma das primeiras expressões do desejo de segregação de classe, isolamento doméstico e espaço aberto privatizado que mais tarde formariam a base da vida suburbana"10 (LAWRENCE apud RAPOSO, 2012, p. 180). Os subúrbios anglo-americanos seguiram as praças residenciais inglesas, contendo casas isoladas umas das outras por espaços bucólicos coletivos, muros que isolavam o entorno e a partir dos quais se controlava o acesso de entrada e saída. A autora aponta ainda que é significativo que esse modelo de subúrbio tenha surgido, no caso inglês, de modo pioneiro em cidades industriais como é o caso de Manchester e Liverpool.

Notadamente, os subúrbios representam uma alternativa de habitat burguês que oferta homogeneidade e exclusão social. Soma-se a isso que esse modelo de habitação emerge justamente de condições urbanas específicas advindas dos processos de modernização burguesa, verificáveis, sumariamente, na Inglaterra e nos EUA. Reconhece-se, assim, que são os subúrbios os reais precursores históricos do que tomo aqui por loteamentos residenciais murados já que suas semelhanças com o modelo atual ligam-se tanto a morfologia dos loteamentos residenciais murados, quanto a aspectos relativos à segregação socioespacial entre as classes sociais.

Em termos globais, nos anos 1970 ressurgem empreendimentos residenciais fechados por muros. Os primeiros exemplares estavam situados em áreas turísticas, sobretudo no estado da Califórnia, nos Estados Unidos. No contexto dos anos 1970, esses empreendimentos eram majoritariamente de prédios de apartamento. Isso permanece até a década de 1980, quando a forma horizontal passa a vigorar, direcionada aos subúrbios.

A partir dos anos 1980 já se verifica uma diversificação e globalização dos loteamentos residenciais murados, que passam também a expandir-se para além das zonas metropolitanas e a direcionarem-se cada vez mais para as bordas da cidade. Em alguns casos, essas habitações passaram a dispor centros comerciais e empresariais em seu interior, no modelo das news towns e edge cities americanas.

10 “[...] represented same of the first expressions of the desire for class segregation, domestic isolation, and privatized open space that later were to form the basis of suburban living" Tradução livre. 
Salvo raras exceções, pode-se afirmar que dos anos 1990 em diante a forma dos loteamentos residenciais murados já havia se espalhado por praticamente todos os cantos do globo. No continente europeu, há prevalência do fenômeno a sul e a leste e na Inglaterra, com ausência a norte e a oeste (RAPOSO, 2012). Desde então, essa forma de confinamento e fragmentação socioespacial está em franca expansão como produto de destaque do mercado imobiliário e como solução paliativa para os problemas relativos à insegurança e o medo nas cidades.

\section{Histórico dos loteamentos residenciais murados no Brasil:}

Temos que os primeiros empreendimentos urbanos fechados datam de 1928 em São Paulo. Entretanto, será só nos anos 1970 que os apartamentos irão se generalizar, no curso da explosão do setor da construção civil e das facilidades de financiamento encontradas no período. ${ }^{11}$ Os loteamentos residenciais murados, por sua vez, se verificariam de forma consolidada nos anos 1980, ao menos em São Paulo e no Rio de Janeiro ${ }^{12}$.

Nos anos 1970 os prédios residenciais ainda estavam localizados na porção central da cidade, e nos anos 1990 a forma dos loteamentos residenciais murados já estava agrupada em áreas mais distantes. Também data de 1990 a concentração de uma gama muito maior de áreas de convívio e equipamentos de uso coletivo, não mais se restringindo aos playgrounds, mas possuindo agora academias, quadras poliesportivas, piscinas e, em alguns casos, como o de Alphaville, centros comerciais e empresariais ${ }^{13}$.

Caldeira (2011) ressalta como o enclausuramento se tornou uma estratégia de marketing dominante após um período em que a busca por descrição e isolamento era motivada pela perseguição política da ditadura militar:

O Ilha do Sul, construído em 1973, é um conjunto de classe média de seis edifícios, cada um com 80 apartamentos de três dormitórios, localizado na zona oeste da cidade (Alto de Pinheiros). Suas principais inovações eram, de um lado, oferecer comodidades como um clube de mais de $10 \mathrm{mil} \mathrm{m}^{2}$ incluindo instalações esportivas, um restaurante e um teatro e, de outro, a segurança: ele é murado e o acesso é controlado por segurança privada. $\mathrm{Na}$ época, o crime não era a principal preocupação da cidade, e a prática de controlar a circulação era na verdade temida por vários grupos: 1973 era o auge da ditadura militar e para muitos qualquer investigação de identidade era vista como ameaçadora. Esse fato indica como o enclausuramento foi

${ }^{11}$ Observa-se o papel do Banco Nacional da Habitação (BNH). Ver em Bonduki (2014).

12 Destaca-se o estudo de Caldeira (2011) acerca de São Paulo e de Ribeiro (1996) sobre o Rio de Janeiro.

${ }^{13}$ Sobre essa forma de empreendimentos urbanos murados do tipo de Alphaville, Aldeia da Serra e Tamboré, ver Teresa Caldeira (2011). 
uma estratégia imobiliária e de marketing que se tornou dominante nas décadas seguinte: hoje, os procedimentos de segurança são requisito em todos os tipos de prédios que aspirem a ter prestígio (CALDEIRA, 2011, p. 261).

Ademais, ressalto algumas diferenciações entre os loteamentos residenciais murados que conhecemos e o modelo norte-americano das gated communities, tradicionalmente referido como um equivalente desses novos habitats urbanos. Em primeiro lugar, no Brasil, as casas são geralmente construídas pelos próprios proprietários, e não pelos incorporadores, no caso dos Estados Unidos. A uniformidade das casas é motivo de recusa no Brasil não apenas pela elite, mas também pelas camadas menos abastadas da população, para as quais esse modelo de padronização existe nas moradias de habitação social e procura ser contornado através de esforços no sentido de modificar a fachada de suas casas e dar algum sentido de "personalidade" para o lar. Em segundo lugar, loteamentos residenciais murados no Brasil não são destacados como espaços de comunidade, a exemplo do que foi feito com as "gated communities". É possível dizer que o ideário de resgate da vida em comunidade é menos sedutor, no Brasil, do que a busca por segurança através da autossegregação.

\section{O fenômeno dos loteamentos residenciais murados e seu viés analítico:}

Condomínios fechados e demais loteamentos residenciais murados têm sido descritos pelos anúncios publicitários enquanto uma "nova forma de morar". Foi o que observou Caldeira (2011) em seu estudo sobre esse tipo de empreendimento e suas correspondentes estratégias de marketing, tendo a cidade de São Paulo como campo. A autora identificou ainda que os anúncios publicitários apostavam na oferta de um ambiente em proximidade do restante da cidade, mas que fosse livre dos inconvenientes da vida urbana, como os barulhos do trânsito de ruas e avenidas muito movimentadas, ou os riscos da criminalidade.

Neste trabalho, exploramos os impactos dos loteamentos residenciais murados tendo como perspectiva o cotidiano da cidade como um todo, considerando os sentidos da realização das formas de morar/habitar integradas ao espaço mais amplo da cidade e compreendendo que loteamentos residenciais murados configuram distintas condições de apropriação do cotidiano da perspectiva dos mais variados tipos de praticantes ordinários da cidade $^{14}$. Coloca-se, portanto, o problema da interpretação teórica desse fenômeno.

Bauman refere-se a essa "nova forma de morar" enquanto "guetos voluntários", em contraste com os "guetos involuntários" das camadas subalternas da população:

${ }^{14}$ Ver em Certeau, Giard e Mayol (2013). 
A cerca separa o "gueto voluntário" dos ricos e poderosos dos muitos guetos forçados dos pobres e excluídos. Para os integrantes do gueto voluntário, os outros guetos são espaços aos quais "nós não vamos". Para integrantes dos guetos involuntários, a área na qual estão confinados (por serem excluídos de outras) é o espaço “do qual não temos permissão de sair” (BAUMAN, 2007, p. 82).

A autossegregação exposta na citação acima elucida também a sua contrapartida inexorável: os espaços fechados através de muros representam também a imposição do distanciamento social no urbano. A fragmentação socioespacial é consequência dessa tomada do espaço urbano onde extensas faixas de terras são circundadas e reservadas a um grupo seleto de moradores. Dessa forma, entendo como adequada a definição de Sposito e Góes para a fragmentação socioespacial como “[...] a existência de uma policentralidade e a conformação de territórios descontínuos, gerando morfologias menos integradas territorialmente" (SPOSITO; GÓES, 2013, p. 295).

A imposição dos muros, mais do que segregar, acarreta distintas condições de apropriação da cidade e seus usos, uma vez que os de "dentro" tem a possibilidade de usufruírem do interior de seus loteamentos residenciais murados e da cidade aberta. Aos de "fora", resta a negação de grandes porções de terra, antes integradas ao espaço público, e agora reservadas aos que podem pagar por ela através da forma dos condomínios fechados e loteamentos residenciais murados.

A problemática dos loteamentos residenciais murados aponta múltiplos direcionamentos passíveis de discussão. Isso se deve ao modo pelo qual esses empreendimentos apropriam-se do espaço urbano, modificando a morfologia das cidades, produzindo a fragmentação socioespacial no sentido enunciado acima, bem como criando microcosmos exclusivos e restritos - o espaço intramuros - onde a sociabilidade se realiza de modo razoavelmente independente e, em certa medida, até antagônico ao modus operandi das sociabilidades no espaço da cidade aberta ${ }^{15}$.

Observa-se, portanto, um lugar outro de tensão entre o espectro privado da casa e o âmbito do público-imediato que é o bairro (CERTEAU; GIARD; MAYOL, 2013). A barreira física do muro impede o trânsito dos outros, "de fora", que conferem heterogeneidade aos espaços. Desse modo, as sociabilidades e a relação entre o privado e o público-imediato, que também é um privado-íntimo, é modificada no sentido da produção da homogeneidade

15 Chamo cidade aberta o espaço público e os espaços privados de convivência comum onde exista a possibilidade do contato entre grupos sociais distintos, o estranhamento, as trocas, a livre-circulação, a mobilidade e a interações entre os objetos físicos e a vida humana. Local de realização das apropriações materiais e simbólicas dos indivíduos na escala da concretude da vida cotidiana. 
intramuros. A eliminação da alteridade, nesse sentido, reduz a possibilidade do cruzamento com o imprevisto e o inesperado da cidade aberta; logo, diminui também um dos elementos constituintes da experiência moderna das cidades e sua decorrente noção de espaço público.

A vida cotidiana, nesse prisma, deixa, num eixo de convivência aproximada, de ser unidade integradora das diferenças (SEABRA, 2004), ao menos na medida em que tais diferenças são atenuadas pelo exclusivismo e pela homogeneidade social. Ainda que o âmbito do vivido não seja constituído apenas no espectro do intramuros, a existência desse espaço produz distintas condições de apropriação do urbano tanto para os que estão "dentro" e necessitam sair para a rua, como para aqueles que estão "fora" e só acessam o intramuros mediante um "convite" de um residente, o que o circunscreve numa relação de nãopertencimento e apropriação rigidamente condicionada e controlada.

Outras considerações são possíveis de serem feitas a respeito desses tipos de empreendimentos residenciais fechados. Objetivamente, cabe aqui ressaltar que a existência dos loteamentos residenciais murados só tem significação em meio a um cenário urbano onde a distinção social e a aquisição da segurança enquanto mercadoria de luxo são produzidas a partir da desigualdade econômica e da marginalidade social. A imprevisibilidade do cotidiano na iminência do contato com o outro, na presença da alteridade urbana na escala dos espaços de realização da vida cotidiana, tornam-se um problema a ser resolvido apenas na medida em que se pese o perigo representado pelo outro e o sentimento de vulnerabilidade que deriva dessa exposição. Sendo assim, tal qual mostra-se a seguir, a origem e consolidação dos loteamentos residenciais murados como mercadoria a ser explorada por um segmento do setor imobiliário só se faz em meio a uma ordem social instável e perigosa, onde o medo se generaliza e adquire uma lógica de desenvolvimento própria (BAUMAN, 2007), o que tensiona nosso atual modelo de desenvolvimento do ponto de vista da vida em relação com o espaço, já que expõe suas contradições acerca das condições de apropriação dos espaços na prática ordinária da vida e na dimensão simbólica dessas vivências.

Dessa forma, o reforço da necessidade de um olhar analítico para o fenômeno da proliferação dos loteamentos residenciais murados envolve a percepção: (a) do modo como alteram a morfologia urbana da cidade, no sentido da produção de subcentros menos integralizados ao tecido da cidade, produzindo novas descontinuidades territoriais e (b) do impacto sobre as formas de apropriação do espaço, tanto do ponto de vista dos residentes desses empreendimentos, quanto daqueles que estão "fora" desse contexto.

Em (a) considera-se objetivamente a permanência da (re)produção das desigualdades socioespaciais através desse modelo de habitação. Em (b) há que se considerar, sobretudo, 
que as condições de apropriação do espaço estão intimamente relacionadas a questão da sociabilidade que, desde Simmel $(2005 ; 2006)$, é onde se estabelecem os nexos entre as estruturas mais macroestruturais da sociedade e a agência inescapável dos atores sociais na materialidade do cotidiano (MAIA, 2001).

\section{Considerações finais}

A busca pela interpretação e compreensão dos processos de produção do espaço urbano constituem um tema transversal a sociologia, a antropologia, a geografia e ao urbanismo. Atribui-se a Lefebvre a inserção da temática espacial na teoria social crítica (LIMONAD, 1999). A teoria lefebvriana atrelou a reflexão articulada entre as dinâmicas espaço-temporais e as relações sociais de produção. O urbano, desse modo, assume um aspecto totalizante, na medida em que as relações de produção são preenchidas também por seu caráter espacial (2016).

Carlos (2018) destaca o espaço enquanto categoria do pensamento e realidade prática, referência para o ser humano enquanto sua condição de existência. Deriva desse argumento sua definição de espaço enquanto condição-meio-produto. É condição já legada pela história, meio inescapável de reprodução da vida vivida e, ao mesmo tempo, produto dos movimentos associados entre a reprodução da vida e os circuitos de acumulação capitalista. A produção do espaço se faz no próprio processo de constituição da história humana, na reprodução das relações sociais de produção.

Chama-se atenção para a temática espacial na observância de que o texto que se seguiu até aqui problematiza um fenômeno intimamente inscrito nas definições de condição-meioproduto. Os loteamentos residenciais murados representam, nesse sentido, uma alteração do ponto de vista da reprodução da vida vivida. Da perspectiva dos residentes, há um microcosmos interno segregado onde parte do cotidiano se realiza. Para aqueles que estão "fora", são os efeitos possíveis da especulação imobiliária e uma nova morfologia urbana que se apresenta a partir de novos espaços isolados ${ }^{16}$.

Objetivou-se, portanto, estabelecer um nexo de análise que aponte para a relevância de associar um elemento da produção imobiliária com suas decorrentes formas de vida cotidiana e apropriação do espaço. Determinações de todos os tipos ou tentativas de descrever com exatidão o modo pelo qual se dá a reprodução da vida vivida a partir desses empreendimentos

\footnotetext{
${ }^{16}$ Novamente, nos referimos a ideia de fragmentação socioespacial de Sposito e Góes (2013), para as quais a fragmentação se dá pela conformação de espaços menos integralizados ao tecido da cidade.
} 
não são o propósito deste trabalho. $\mathrm{O}$ que se fez foi ressaltar as implicações mais imediatas desse fenômeno articuladas a reflexão social crítica, na contribuição para os estudos que visem o desdobramento dessa temática.

AGRADECIMENTOS: Agradeço ao Professor Dr. Rafael Alves Orsi, que orientou a pesquisa na qual este trabalho é parte e ao $\mathrm{CNPq}$, agência de fomento da dissertação de mestrado em processo.

\section{REFERÊNCIAS}

BAUMAN, Zygmunt. Modernidade líquida. Rio de Janeiro: Zahar, 2001.

BAUMAN, Zygmunt. Tempos líquidos. Rio de Janeiro: Zahar, 2007.

BENJAMIN, Walter. Baudelaire e a modernidade. São Paulo: Autentica, 2015.

BONDUKI, Nabil Georges. Os pioneiros da habitação social. Volume 1. São Paulo: Editora UNESP; Edições Sesc SP, 2014.

CALDEIRA, Teresa. Cidade de Muros: crime, segregação e cidadania em São Paulo. São Paulo: Edusp, 2011.

CARLOS, Ana Fani Alessandri. A Condição Espacial. São Paulo: Contexto, 2018.

CERTEAU, Michel; GIARD, Luce; MAYOL, Pierre. Invenção do Cotidiano. Volume 2. Petrópolis: Editora Vozes, 2013.

DAVIS, Mike. Planeta Favela. São Paulo: Boitempo Editorial, 2006.

EHRENBERG, Alain. O Culto da Performance. São Paulo: Ideias e Letras, 2010.

ENGELS, Friedrich. A situação da classe trabalhadora na Inglaterra. São Paulo:

Boitempo Editorial, 2008.

HARVEY, David. O enigma do capital e as crises do capitalismo. São Paulo: Boitempo Editorial, 2011.

JACOBS, Jane. Morte e vida nas grandes cidades. São Paulo: Martins Fontes, 2000.

LEFEBVRE, Henri. O direito à cidade. São Paulo: Centauro Editora, 2016.

LIMONAD, Ester. Reflexões sobre o espaço, o urbano e a urbanização. GEOgrafia, Ano 1, n. 1, 1999. Disponível em:

https://www.researchgate.net/publication/303895969_Reflexoes_sobre_o_Espaco_o_Urbano_ e_a_Urbanizacao. Acesso em: 23 out. 2019. 
MAIA, R. C. M. Sociabilidade: apenas um conceito? GERAES - Revista de Comunicação Social, n. 53, 2001. Disponível em:

https://www.researchgate.net/profile/Rousiley_Maia/publication/317051024_Sociabilidade_a penas_um_conceito/links/5923241caca27295a8a7e774/Sociabilidade-apenas-umconceito.pdf. Acesso em: 23 out. 2019.

RAPOSO, Rita. Condomínios fechados, tempo, espaço e sociedade: uma perspectiva histórica. Cadernos Metrópole, v. 14, n. 27, p. 171-196, 2012.

RIBEIRO, L. C. de Q. Dos cortiços aos condomínios fechados. Rio de Janeiro: Civilização Brasileira, 1996.

RODRIGUES, Arlete Moysés. Propriedade fundiária urbana e controle socioespacial urbano. In: COLOQUIO INTERNACIONAL DE GEOCRÍTICA. EL CONTROL DEL ESPACIO Y LOS ESPACIOS DE CONTROL BARCELONA, 13., 2014, Barcelona. Anais [...].

Barcelona, maio 2014. p. 5-10. Disponível em:

http://www.ub.edu/geocrit/coloquio2014/Arlete\%20Moyses\%20Rodrigues.pdf. Acesso em: 23 out. 2019.

SASSEN, Saskia. Expulsões: Brutalidade e complexidade na economia global. Rio de Janeiro/ São Paulo: Paz \& Terra, 2016.

SEABRA, Odette. Territórios do uso: cotidiano e modo de vida. Cidades. v. 1, n. 2, p. 181206, 2004.

SIMMEL, Georg. As grandes cidades e a vida do espírito. Mana, Rio de Janeiro, v. 11, n. 2, p. 557-591, 2005.

SIMMEL, Georg. Questões fundamentais de sociologia: indivíduo e sociedade. Trad. Pedro Caldas. Rio de Janeiro: Zahar, 2006.

SPOSITO, M. E. B; GÓES, E. M. Espaços fechados e cidades: insegurança urbana e fragmentação socioespacial. São Paulo: Editora Unesp, 2013. 


\section{Como referenciar este artigo}

CAVALCANTI, Murilo Petito. Considerações sobre a experiência urbana dos loteamentos residenciais murados. Rev. Sem Aspas, Araraquara, v. 8, n. 2, p. 240-257, jul./dez., 2019. eISSN: 2358-4238. DOI: https://doi.org/10.29373/sas.v8i2.13085

Submetido em: 01/11/2019

Aprovado em: 19/12/2020

Publicado em: 30/12/2019 